\title{
Isoflavones Induce BEX2-Dependent Autophagy to Prevent ATR-Induced Neurotoxicity in SH-SY5Y Cells
}

\author{
Peng Li Kun Ma Hao-Yu Wu Yan-Ping Wu Bai-Xiang Li \\ Department of Hygienic Toxicology, School of Public Health, Harbin Medical University, Harbin, P. R. \\ China
}

\section{Key Words}

Atrazine $\cdot$ Neurotoxicity $・$ Prevention $\cdot$ Autophagy $・$ Isoflavones $・$ Brain-expressed X-linked 2

\begin{abstract}
Background/Aims: Atrazine (ATR) is a broad-spectrum herbicide in wide use around the world. However, ATR is neurotoxic and can cause cell death in dopaminergic neurons, leading to neurodegenerative disorders. Autophagy is the basic cellular catabolic process involving the degradation of proteins and damaged organelles. Studies have shown that certain plant compounds can induce autophagy and prevent neuronal cell death. This prompted us to investigate plant compounds that might reduce the neurotoxic effects of ATR. Methods: By CCK-8 and flow cytometry, we tested the ability of five candidate compounds-isoflavones, resveratrol, quercetin, curcumin, and green tea polyphenols-to protect cells from ATR. Changes in the expression of tyrosine hydroxylase (TH) and brain-expressed X-linked 2 (BEX2), autophagy-related proteins and key factors in mTOR signaling, were detected by Western blotting. Results: Isoflavones had the strongest activity against ATR-induced neuronal apoptosis. ATR reduced the expression of TH and BEX2, whereas isoflavones increased TH and BEX2 expression. In addition, ATR inhibited autophagy, whereas isoflavones induced autophagy through the accumulation of LC3-II and decreased expression of p62; this effect was abolished by 3-methyladenine (3-MA). Furthermore, BEX2 siRNA abolished isoflavonemediated autophagy and neuroprotection in vitro. Conclusion: Isoflavones activate BEX2dependent autophagy, protecting against ATR-induced neuronal apoptosis.
\end{abstract}

\section{Introduction}

The triazine herbicide atrazine (ATR) is widely used to control certain annual broadleaf and grass weeds in agriculture around the world because of its effectiveness in crop protection and low price. Given its widespread use on a variety of crops, ATR can be frequently detected in surface and ground water sources [1-9]. Because of its mobility and long-term residual P. Li and K. Ma contributed equally to this work. 
persistence in the environment, the detection of ATR in both ecosystems and humans has been reported. Chronic ATR exposure results in high accumulative levels in multiple organs and tissues [10-14]. It has been shown that ATR and its metabolites, known as environmental endocrine disruptors, affect the central nervous and reproductive systems [15-17]. In terms of its nervous system toxicity, ATR decreases the level of striatal dopamine (DA) and the number of tyrosine hydroxylase (TH)-positive dopaminergic neurons in rodents, resulting in pathology and behavior similar to that of a Parkinson's disease (PD) model. Epidemiological evidence suggests that rural farmers have a higher incidence of PD with high and consistent herbicide exposure [18-23].

The toxicity of ATR to the nervous system shows that it can influence the functioning of synaptic vesicles and synaptic bodies, interfering with the storage and uptake of DA in synaptic vesicles and disrupting the function of the thalamic neuroendocrine system [24,25]. Furthermore, ATR can significantly change the levels of catecholamine neurotransmitters, especially norepinephrine (NE) and DA. In addition to the effects of ATR on DA in the nervous system, studies have shown that ATR induces apoptosis and reactive oxygen species (ROS) levels in SH-SY5Y cells $[26,27]$. Other results show that ATR induces apoptosis in PC12 cells by altering the expression of p53, caspase-3 and caspase-9 [28]. Recently, some researchers have described the mechanisms of ATR-induced neuronal cell death $[29,30]$, which can include autophagy, apoptosis, and necrosis.

Autophagy is a so-called 'self-eating' cellular mechanism that involves the clearance of misfolded proteins, preventing the toxic accumulation of misfolded proteins and damaged organelles and thereby achieving the metabolic needs of cells [31]. Recent studies have indicated that different types of cancer cells undergo autophagy in response to anti-cancer therapies. For instance, Faisal et al. investigated the anti-glioma potential of curcumin in vitro, and further examined the molecular mechanisms of curcumin-induced cell death in human malignant glioma [32]. Brain-expressed X-linked 2 (BEX2, a member of the BEX family) is abundantly expressed in the central nervous system, with high levels in the pituitary cerebellum [33]. Evidence has shown that BEX2 can suppress mitochondrial apoptosis. In gliomas, overexpression of BEX2 inhibits tumor growth in vitro and in vivo [34]. Thus, autophagy is being increasingly studied as a new type of treatment for various cancers and neurological degenerative diseases.

In recent years, there has been increasing interest in the neuroprotective effects of natural plant compounds. For example, carnosic acid protects against 6-hydroxydopamine (6-OHDA)-induced apoptosis by inducing autophagy in SH-SY5Y cells [35]. Similarly, resveratrol protects against rotenone-induced neuronal apoptosis by regulating autophagic flux [36].

In this study, we selected five compounds as candidates to explore their ability to protect SH-SY5Y cells from ATR-induced damage: isoflavones, resveratrol, quercetin, curcumin, and green tea polyphenols. Among these candidates, we found that isoflavones had the strongest activity against ATR toxicity. Our results indicate that BEX2 mediates autophagy in SH-SY5Y cells and that isoflavones can attenuate ATR-induced neurotoxicity by inducing autophagy through BEX2.

\section{Materials and Methods}

\section{Reagents and antibodies}

The human neuroblastoma SH-SY5Y cell line was obtained from the Cell Bank of the Chinese Academy of Sciences. ATR (CAS:1912-24-9) and Dulbecco's modified Eagle medium (DMEM) high-glucose were from Life Technologies (Carlsbad, CA, USA). Fetal bovine serum (FBS) was from Biological Industries (Kibbutz Beit-Haemek, Israel) and the Cell Counting Kit (CCK-8) was from Dojindo (Tokyo, Japan). The BCA protein assay kit was from Beyotime Biotechnology (Shanghai, China). Rapamycin were from Ruiyong Biological (Shanghai, China). 3-methyladenine (3-MA) and curcumin were purchased from Sigma (St. Louis, MO, USA). Isoflavones, resveratrol, quercetin, and green tea polyphenols were purchased from China Standard Material 


\section{Cellular Physiology Cell Physiol Biochem 2017;43:1866-1879 \begin{tabular}{l|l|l} 
and Biochemistry $10.1159 / 000484075$ & $\begin{array}{l}\text { C) } 2017 \text { The Author(s). Published by S. Karger AG, Basel } \\
\text { www.karger.com/cpb }\end{array}$ \\
\hline
\end{tabular}}

Li et al.: Isoflavones Against ATR in SH-SY5Y Cells

Center (Beijing, China). BEX2 and TH were from Santa Cruz Biotechnology Inc. (Santa Cruz, CA, USA). p-S6 and S6 were provided by Cell Signaling Technology (Danvers, MA, USA). LC3B and p62 were from Abcam (New Territories, Hong Kong, China). Alkaline phosphatase-goat anti-rabbit IgG and alkaline phosphatasegoat anti-mouse IgG were from ZSGB-BIO (Beijing, China). SYBR Premix Ex Taq II was from Takara Bio Inc. (Otsu, Shiga, Japan) and primers were from Generay Biological Engineering Co. (Shanghai, China). The stock solutions of isoflavones, resveratrol, quercetin, curcumin, green tea polyphenols, rifampicin, ATR, and 3-MA were prepared at $100 \mathrm{mM}$ in dimethyl sulphoxide (DMSO) and stored at $-20^{\circ} \mathrm{C}$. Drug stocks were prepared for single use to avoid repeated freeze-thaw cycles and diluted to the desired concentration as needed.

\section{Cell culture}

SH-SY5Y cells were cultured in DMEM high-glucose containing 10\% FBS, 100 IU/ml penicillin and 100 $\mathrm{mg} / \mathrm{ml}$ streptomycin at $37^{\circ} \mathrm{C}$ with $5 \% \mathrm{CO}_{2}$. All experiments were performed at cell confluence of $70-80 \%$ between passages 26 and 33. The cells were plated at an appropriate density according to the different experimental protocols utilized in this work.

\section{CCK8 cell viability assay}

Cellular viability was assayed by CCK- 8 assay to detect mitochondria in living cells. Briefly, the cells were plated onto 96 -cell plates. When the cultures reached $70-80 \%$ confluence, the culture medium was removed and the cells were then incubated for $24 \mathrm{~h}$ in the presence of various doses of isoflavones, resveratrol, quercetin, curcumin, or green tea polyphenols $(5,10,20,50$, and $100 \mu \mathrm{M})$. After $24 \mathrm{~h}$, the cultures were washed three times with PBS and cultured for $24 \mathrm{~h}$ with $250 \mu \mathrm{M}$ ATR. At the indicated time after treatment, the CCK8 reagent $(0.5 \mathrm{mg} / \mathrm{ml})$ was then added to the cell culture medium and incubated at $37^{\circ} \mathrm{C}$ for $1 \mathrm{~h}$. The absorbance was evaluated at $450 \mathrm{~nm}$ using a microplate reader (Bio-Tek Elx800, Bio-Tek, Norcross, CA, USA).

\section{Determination of apoptotic cell population}

The cells were treated with isoflavones, resveratrol, quercetin, curcumin, or green tea polyphenols (5 $\mu \mathrm{M})$. After $24 \mathrm{~h}$, the cultures were washed three times with PBS and cultured for $24 \mathrm{~h}$ with $250 \mu \mathrm{M}$ ATR. To determine the apoptotic cell population, cells were stained with FITC-conjugated annexin V and propidium iodide (PI) using a Dead Cell Apoptosis Kit (Invitrogen, Carlsbad, CA, USA) according to the manufacturer's instructions. In each analysis, 10, 000 events were counted using a BD flow cytometer (BD, Franklin Lakes, NJ, USA).

\section{Western blot analysis}

The cells were treated with $5 \mu \mathrm{M}$ isoflavones for $24 \mathrm{~h}$ followed by exposure to $250 \mu \mathrm{M}$ ATR for $24 \mathrm{~h}$, then collected and lysed for $30 \mathrm{~min}$ in lysis buffer (Beyotime Biotechnology) containing $1 \mathrm{mM}$ phenylmethanesulfonyl fluoride (Beyotime Biotechnology). The cells were then centrifuged at 12, $000 \mathrm{rpm}$ for $10 \mathrm{~min}$ at $4^{\circ} \mathrm{C}$. Protein concentrations in the cell lysates were determined by the BCA protein assay (Beyotime Biotechnology). Equal amounts of cell lysates (50 $\mu \mathrm{g}$ ) were separated by $10 \%$ SDS-PAGE. The proteins were transferred to polyvinylidene difluoride membranes and blocked with $1 \%$ bovine serum albumin with $0.05 \%$ Tween 20 in PBS for $30 \mathrm{~min}$, followed by incubation with TH, BEX2, P-S6, S6, LC3 or p62 antibodies (1:1000 dilution), and with a $\beta$-actin antibody (1:1000 dilution, ImmunoWay Biotechnology, Newark, DE, USA) as a control, at $4^{\circ} \mathrm{C}$ overnight. After three washes with Tris-buffered saline (TBS) and $0.05 \%$ Tween 20 (TBST), the membranes were incubated with alkaline phosphatase-goat anti-rabbit IgG (1:5000 dilution; ZSGB-BIO) or alkaline phosphatase-goat anti-mouse IgG (1:5000 dilution; ZSGB-BIO) for $1 \mathrm{~h}$. Western Blue stabilized substrate alkaline phosphatase (Promega Corporation, Madison, WI, USA) was used to detect the immunoreactive signals. The air-dried membranes were imaged using an image analyzer (Bio-Rad Laboratories, Hercules, CA, USA). Band intensities were measured using Image v v1.50 software.

\section{Quantitative real-time PCR}

Total RNA was isolated using Trizol (Invitrogen) according to the manufacturer's instructions. A SYBR Premix Ex Taq II Reagent Kit and gDNA Eraser reverse transcriptase were used to obtain cDNA, according to the manufacturer's instructions (Takara, Japan). The following primer sequences were used: human $\beta$-actin: forward CTACCTCATGAAGATCCTCACCGA, reverse TTCTCCTTAATGTCACGCACGATT; humannLC3: forward 
TACGGAAAGCAGCAGTGT, reverse GAAGGCAGAAGGGAGTGT (Generay, Shanghai, China). For polymerase chain reaction (PCR) analysis, samples were normalized to $\beta$-actin expression by calculating $\triangle \mathrm{CT}$ (CT target gene - CT actin). The $2^{-\Delta \Delta C T}$ method was used to calculated the relative amount of target mRNA. Cells were pretreated with $5 \mu \mathrm{M}$ isoflavones for $24 \mathrm{~h}$, followed by exposure to $250 \mu \mathrm{M}$ ATR for $24 \mathrm{~h}$.

Transient transfection of small interfering RNA (siRNA)

Cell were plated on 35-mm plastic tissue culture dishes at a density of $1.2 \times 10^{6}$ cells per dish. When $70 \%$ to $80 \%$ confluence was reached, cells were transfected with $50 \mathrm{nM} \mathrm{BEX2} \mathrm{siRNA} \mathrm{or} \mathrm{non-targeting} \mathrm{control}$ (RiBOBio, Guangzhou, China) using Lipofectamine 2000 (Invitrogen) according to the manufacturer's instructions. Cells were pretreated with $5 \mu \mathrm{M}$ isoflavones for $24 \mathrm{~h}$ and were then treated with $250 \mu \mathrm{M}$ ATR for $24 \mathrm{~h}$.

\section{Statistical analysis}

Each experiment was performed at least three times and results are presented as mean \pm SD. A oneway analysis of variance (ANOVA) was used to determine the differences between experimental groups. As post hoc analysis, Fisher's Least Significant Difference test (LSD) was used for comparisons between multiple group means. A value of $p<0.05$ was considered to be significant.

\section{Results}

Pretreatment with candidate compounds prevents the loss of cell viability and cell death induced by ATR

In previous reports, we demonstrated that ATR reduces cell viability in a time- and dose-dependent manner and found that the median lethal dose $\left(\mathrm{LD}_{50}\right)$ of ATR was $250 \mu \mathrm{M}$ after a $24 \mathrm{~h}$ exposure [27]. Therefore, we used ATR at $250 \mu \mathrm{M}$ for further experiments. We quantified cell viability of ATR-treated SH-SY5Y cells using the CCK-8 assay, with and without pretreatment with varying concentrations $(5,10,20,50,100 \mu \mathrm{M})$ of five candidate compounds (isoflavones, resveratrol, quercetin, curcumin, green tea polyphenols) (Fig. 1A). Though ATR reduced the cell viability to $43.57 \pm 7.95 \%$ of the control cells, cells cultured with isoflavones $(5-100 \mu \mathrm{M})$ for $24 \mathrm{~h}$ prior to treatment with ATR showed significantly increased viability, particularly at an isoflavone concentration of $5 \mu \mathrm{M}$.

In order to further determine the protective effects of the five compounds (at $5 \mu \mathrm{M}$ ) on ATR-treated SH-SY5Y cells, we conducted annexin V/PI double staining and analyzed apoptotic cell populations using a flow cytometer. About $19.83 \pm 1.81 \%$ of the cells treated with ATR were detected in quadrant Q4+Q2, which indicates early and late apoptosis. All compounds were effective in reducing ATR-induced cell apoptosis, with the effects of isoflavones and curcumin reaching significance (Fig. 1B, C). As isoflavones are more easily acquired, we chose to focus on isoflavones $(5 \mu \mathrm{M})$ for further experiments.

\section{Isoflavones partially prevent the effects of ATR on TH expression}

Previous studies have shown that ATR exposure reduces dopamine secretion by reducing the expression of TH [24]. TH is essential for synthesizing dopamine in dopaminergic neurons, which is important for the normal functioning of the nervous system [37]. To determine whether isoflavones prevent the effect of ATR on TH expression, we analyzed the expression of TH in ATR- and isoflavone-treated cells by western blotting. The results showed that TH expression is significantly affected by ATR, while isoflavones partially prevent the effects of ATR on TH expression (Fig. 2A, B).

\section{Isoflavones induce autophagy}

Autophagy plays a cytoprotective role in maintaining cellular homeostasis by removing damaged or dysfunctional cellular organelles [38]. In order to determine whether the protective effects of isoflavones against ATR-induced cell death were caused by autophagy, we examined the levels of LC3 protein, particularly LC3-II, an autophagosome marker. We found 


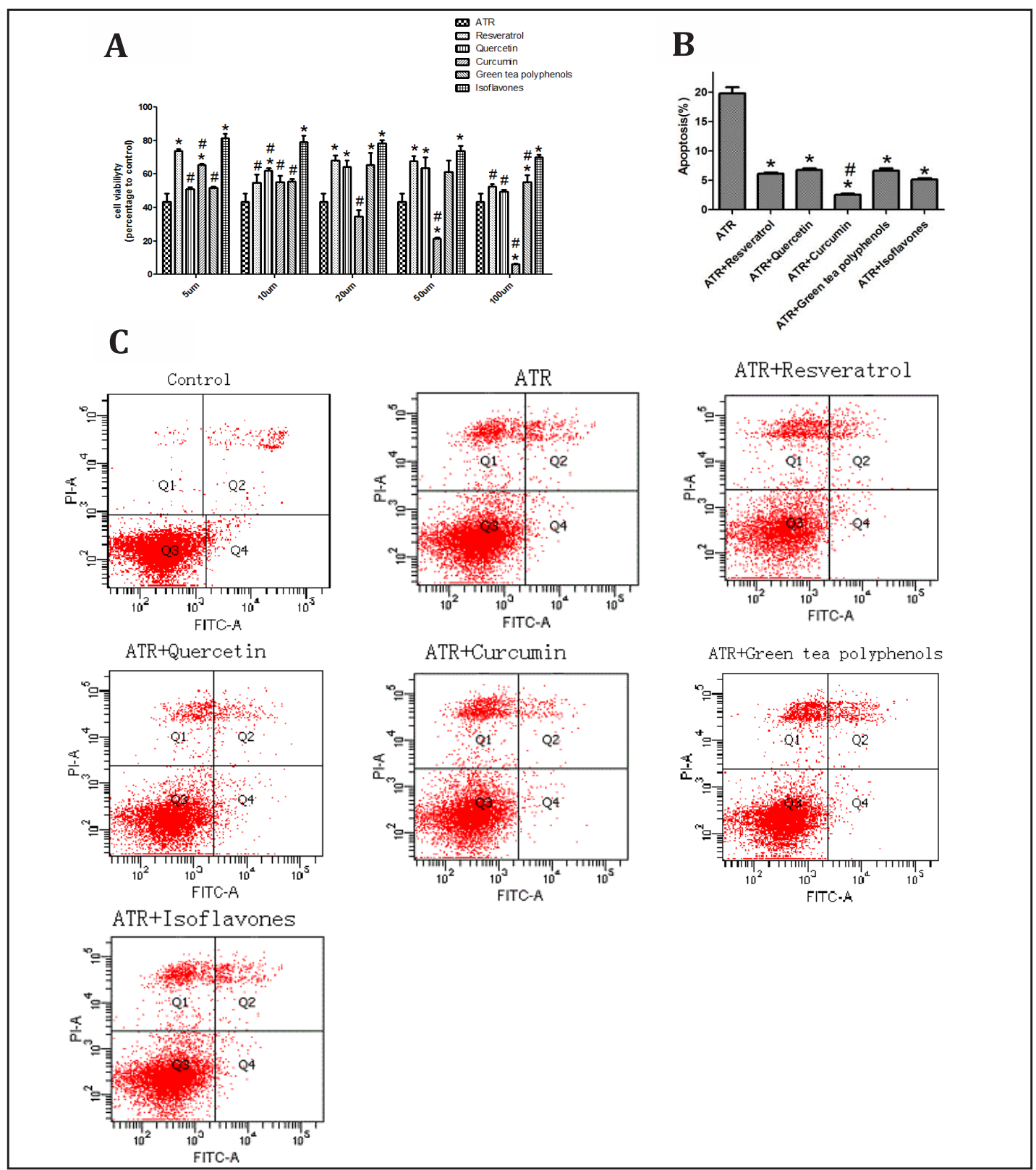

Fig. 1. Candidate compounds protect SH-SY5Y cells against ATR-induced apoptosis. (A) Cell viability assay. Cells were pretreated with various doses of five candidate compounds for $24 \mathrm{~h}$ and then subjected to $250 \mu \mathrm{M}$ ATR for the next $24 \mathrm{~h}$. Cell viability was determined by CCK-8 assay using spectrophotometry at $450 \mathrm{~nm}$; (B, C) Flow cytometry. Cells were treated with ATR and any of the five compounds $(5 \mu \mathrm{M})$ as described in panel A, stained with annexin V/PI, and then analyzed by flow cytometry. Early and late apoptotic cell populations $(\mathrm{Q} 4+\mathrm{Q} 2$ quadrant) are represented as percentages of total cells analyzed. Data represent the mean \pm SD of three independent experiments. Statistical significance was determined by an LSD post-hoc test. ${ }^{*}$ p $<0.05$ compared to isoflavones. ${ }^{*}$ p $<0.05$ compared to ATR.

that the conversion of LC3-I to LC3-II as well as the total levels of LC3 proteins increased in SH-SY5Y cells treated with isoflavones, as did the total levels of LC3 mRNA (Fig. 3A, C). In addition, isoflavones $(5 \mu \mathrm{M})$ increased the protein expression of LC3-II, which peaked at $24 \mathrm{~h}$, similar to our observations of LC3 mRNA (Fig. 3B, D). Cotreatment with ATR and isoflavones induced more LC3 expression than ATR alone, in line with the mRNA expression 


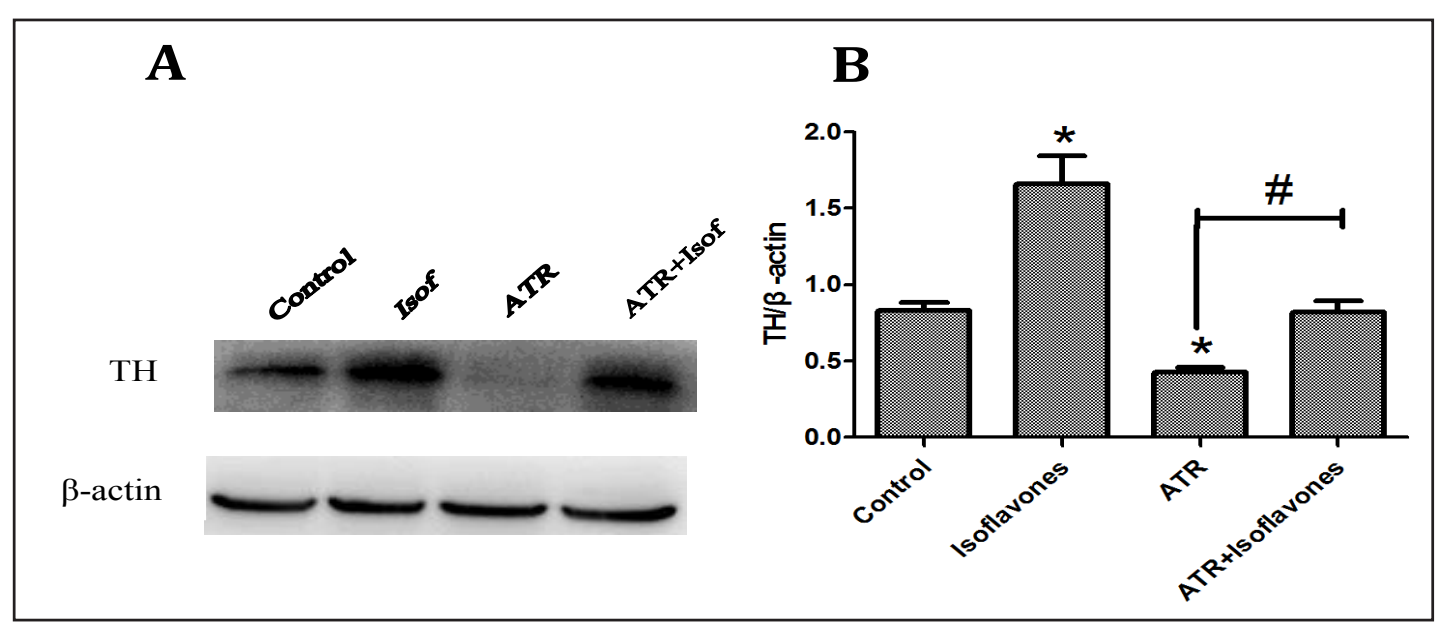

Fig. 2. Isoflavones partially prevent the effects of ATR on TH expression. (A, B) Cells were pretreated with/ without $5 \mu \mathrm{M}$ isoflavones (Isof) for $24 \mathrm{~h}$, and then treated with/without $250 \mu \mathrm{M}$ ATR for the next $24 \mathrm{~h}$. The levels of TH were determined by western blotting followed by quantitative analysis using ImageJ. Data were normalized to $\beta$-actin levels. Data represent the mean \pm SD of three independent experiments. Statistical significance was determined by an LSD post-hoc test. ${ }^{*} \mathrm{p}<0.05$ between groups. ${ }^{*} \mathrm{p}<0.05$ compared to control.

results as determined by PCR (Fig. 3E, F). Treatment with 3-MA inhibited autophagy, as expected, and LC3 expression were decreased in cells treated with a combination of 3-MA, ATR, and isoflavones compared to cells treated with only ATR and isoflavones (Fig. 3E). In order to further demonstrate that isoflavones induce autophagy, we measured the expression pattern of another autophagic marker, p62, which serves to link ubiquitinated proteins to the autophagic machinery via LC3 [39]. The results show that isoflavones also decrease the expression of p62 (Fig. 3A). These results indicate that isoflavones induce autophagy.

\section{BEX2 induction by isoflavones protects cells from ATR}

It has been reported that BEX2 can inhibit human glioma tumor growth. To determine whether BEX2 is associated with the neuroprotective effect of isoflavones, SH-SY5Y cells were treated with various doses of isoflavones over a $24 \mathrm{~h}$ period. Isoflavones (5-100 $\mu \mathrm{M})$ induced BEX2 expression (Fig. 4A). In addition, isoflavones (5 $\mu \mathrm{M})$ increased the protein levels of BEX2 in a time-dependent manner, with BEX2 expression peaking after $12 \mathrm{~h}$ of isoflavone treatment and sustained up to $24 \mathrm{~h}$ (Fig. 4B). Next, the role of BEX2 in isoflavonemediated protection against ATR toxicity was investigated. ATR reduced BEX2 expression, whereas isoflavones increased BEX2 expression. In addition, isoflavones partially prevented the effect of ATR on BEX2 expression (Fig. 4C). These results demonstrate that isoflavones increase the expression of BEX2 and suggest that BEX2 induction by isoflavones may contribute to cytoprotection against ATR.

Isoflavones prevent ATR-induced neuronal death through BEX2-dependent autophagy

To elucidate the role of BEX2 in the induction of autophagy by isoflavones, we measured LC3-II expression levels under BEX2 knockdown conditions. siRNA-mediated knockdown of BEX2 decreased isoflavone-mediated LC3-II expression (Fig. 5A), suggesting that BEX2 induction by isoflavones activates autophagy. In order to demonstrate that isoflavones act though BEX2-induced autophagy to prevent ATR-induced cell death, we measured LC3-II expression levels under BEX2 knockdown conditions, as shown in Fig. 5B. To further verify that BEX2 has a protective effect against ATR-induced cell death, we measured cell viability by CCK-8 assay. BEX2 siRNA increased the cell death induced by ATR, even in the presence of isoflavones (Fig. 5C). These results demonstrate that the protective effects of isoflavones on ATR-induced neuronal cell death are mediated by BEX2-dependent induction of autophagy. 
Fig. 3. Isoflavones induce autophagy. (A) Dose-dependent effect of isoflavones on LC3-II and p62 expression in SH-SY5Y cells. Whole cells treated with isoflavones $\quad$ 5-100 $\mu \mathrm{M}$, Isof) for $24 \mathrm{~h}$ were lysed for western blotting and quantitative analysis using ImageJ. Data were normalized to $\beta$-actin levels. (B) Duration-dependent effect of isoflavones on LC3-II expression in SH-SY5Y cells. Whole cells that had been treated with isoflavones $(5 \mu \mathrm{M})$ for $6-24$ h were lysed for western blotting and quantitative analysis using ImageJ. Data were normalized to $\beta$-actin levels. (C, D) Real-time PCR analysis of LC3 mRNA expression in cells treated with different doses and durations of isoflavones. (E) SH-SY5Y cells were pretreated with/without $5 \mu \mathrm{M}$ isoflavones for $24 \mathrm{~h}$, then treated with/without $250 \mu \mathrm{M}$ ATR in the presence/ absence of $2 \mu \mathrm{M}$ 3-MA for the next $24 \mathrm{~h}$. LC3 expression was examined by western blotting and quantitative analysis using Image J. Data were normalized to $\beta$-actin levels. (F) Real-time PCR analysis of LC3 mRNA expression. Cells were treated with ATR and isoflavones as described in panel $E$.

Data represent the mean \pm SD of three independent experiments. Statistical significance was determined by an LSD post-hoc test. ${ }^{\#}$ p $<0.05$ compared between groups. ${ }^{*}$ p $<0.05$ compared to control.
B $\quad$ C $\quad 6 \quad 12 \quad 24$

LC3

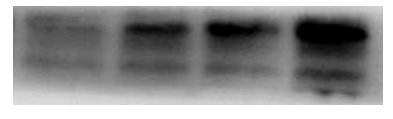

P62

$\beta$-actin

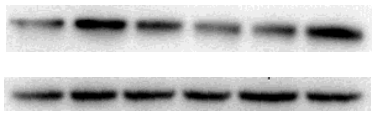

$\beta$-actin
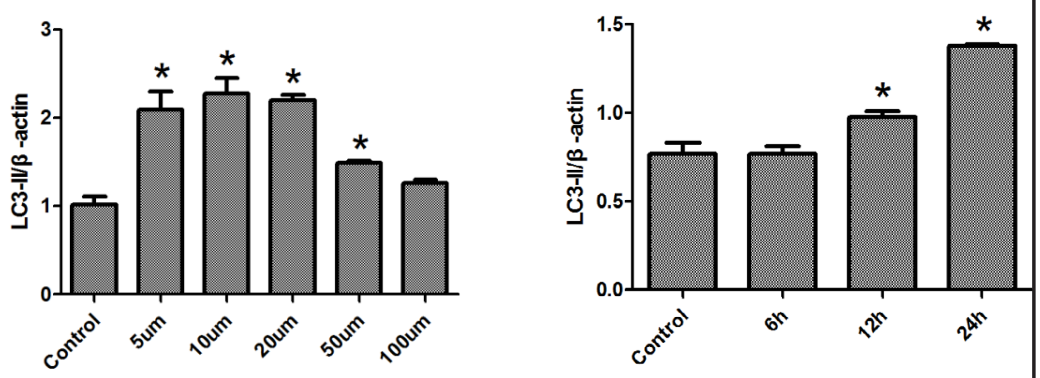

C

D
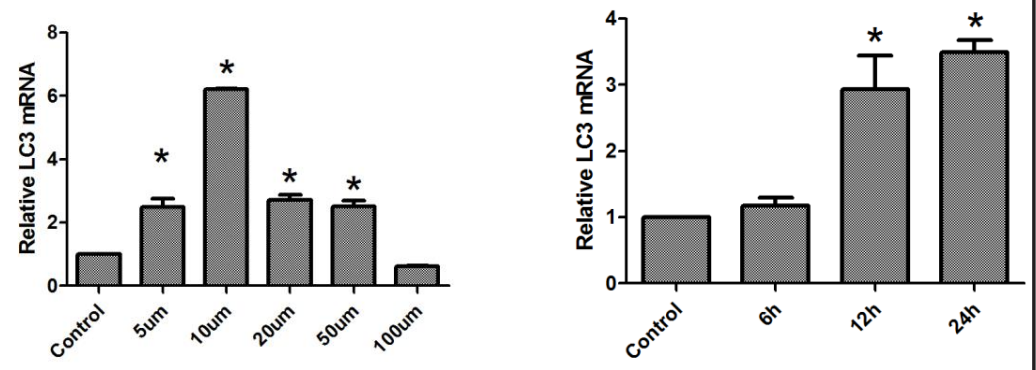

LC3

$\beta$-actin

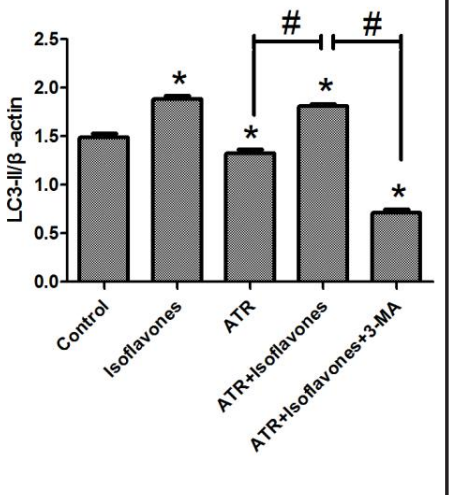

F

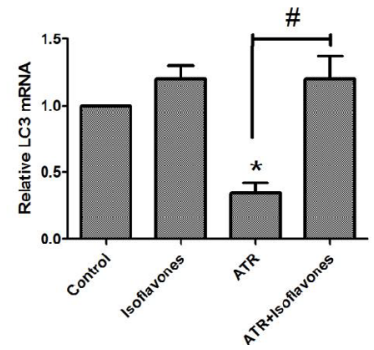




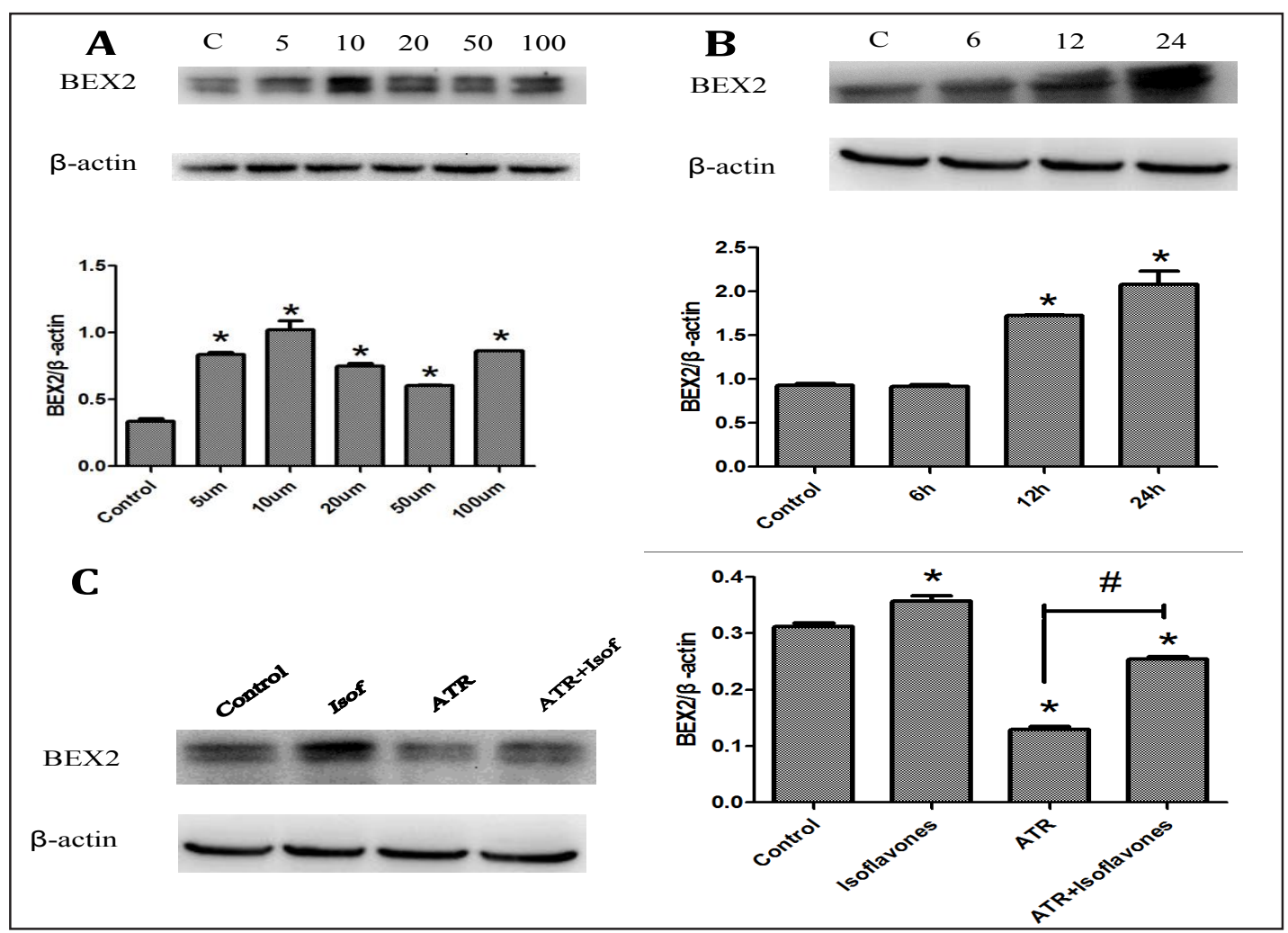

Fig. 4. ATR-mediated inhibition of BEX2 expression is prevented by isoflavones. (A) Cells were treated with 0-100 $\mu \mathrm{M}$ isoflavones (Isof) for $24 \mathrm{~h}$. BEX2 expression was determined by western blotting and quantitative analysis using ImageJ. Data were normalized to $\beta$-actin levels. (B) Cells were treated with $5 \mu \mathrm{M}$ isoflavones for 6-24 h. BEX2 expression was determined by western blotting and quantitative analysis using ImageJ. Data were normalized to $\beta$-actin levels. (C) Cells were treated with/without $5 \mu \mathrm{M}$ isoflavones for $24 \mathrm{~h}$, then treated with/without $250 \mu \mathrm{M}$ ATR for the next $24 \mathrm{~h}$. BEX2 expression was determined by western blotting and quantitative analysis using ImageJ. Data were normalized to $\beta$-actin levels. Data represent the mean \pm SD of three independent experiments. Statistical significance was determined by an LSD post-hoc test. \# $\mathrm{p}<0.05$ compared between groups. ${ }^{*} \mathrm{p}<0.05$ compared to control.

\section{Isoflavones mediate autophagy by an mTOR-dependent pathway}

To explore whether isoflavones mediate autophagy by an mTOR-dependent pathway, we treated cells with the mTOR inhibitor rapamycin. Upon treatment with rapamycin $(2 \mu \mathrm{M}$ for $24 \mathrm{~h}$ ), the downstream ribosomal protein S6 was inactivated (Fig. 6A). However, co-treatment with isoflavones partially maintained the activity of the mTOR-p70S6K pathway (Fig. 6A). Rapamycin increased the level of basal autophagy, and further increased the production of LC3-II in isoflavone-treated cells (Fig. 6A). Moreover, the ATR-induced reduction of p-S6 and LC3-II expression was partly reversed by cotreatment with ATR and isoflavones. In addition, the levels of BEX2 were reduced following rapamycin treatment (Fig. 6B). Taken together, these data indicate that isoflavones induce autophagy through an mTOR-dependent pathway.

\section{Discussion}

Increasing evidence suggests that ATR as a neurotoxic herbicide selectively targets the dopaminergic system $[25,40]$. Recently, plant compounds have been shown to play a significant role in neurological protection [35]. Here, we provide evidence that isoflavones prevent ATR-induced neuronal apoptosis by cell viability and apoptosis studies. ATR reduces 
Fig. 5. The protective effects of isoflavones are mediated by BEX2-dependent autophagy. (A) Cells were transfected with si-BEX2, and then treated with $5 \mu \mathrm{M}$ is of lavones (Isof) for 24 h. Knockdown efficiency was confirmed by BEX2 and LC3 western blotting and quantitative analysis using ImageJ. Data were normalized to $\beta$-actin levels. (B) Cells were transfected with/without si-BEX2, then treated with/ without $5 \mu \mathrm{M}$ isoflavones for $24 \mathrm{~h}$, and then treated with/ without 250 $\mu \mathrm{M}$ ATR for the next $24 \mathrm{~h}$. BEX2 expression was determined by western blotting and quantitative analysis using ImageJ. Data were normalized to $\beta$-actin levels. (C) Cell viability was determined by CCK-8 assay. Data represent the mean \pm SD of three independent experiments. Statistical significance was determined by LSD post-hoc test. ${ }^{*} \mathrm{p}<0.05$ compared between groups. ${ }^{*} \mathrm{p}<0.05$ compared to control.

the number of TH-positive cells in the nervous system. However, TH is the rate-limiting enzyme involved in DA synthesis in dopaminergic neurons, which is important for the normal functioning of the nervous system [37]. Our results show that isoflavones increased
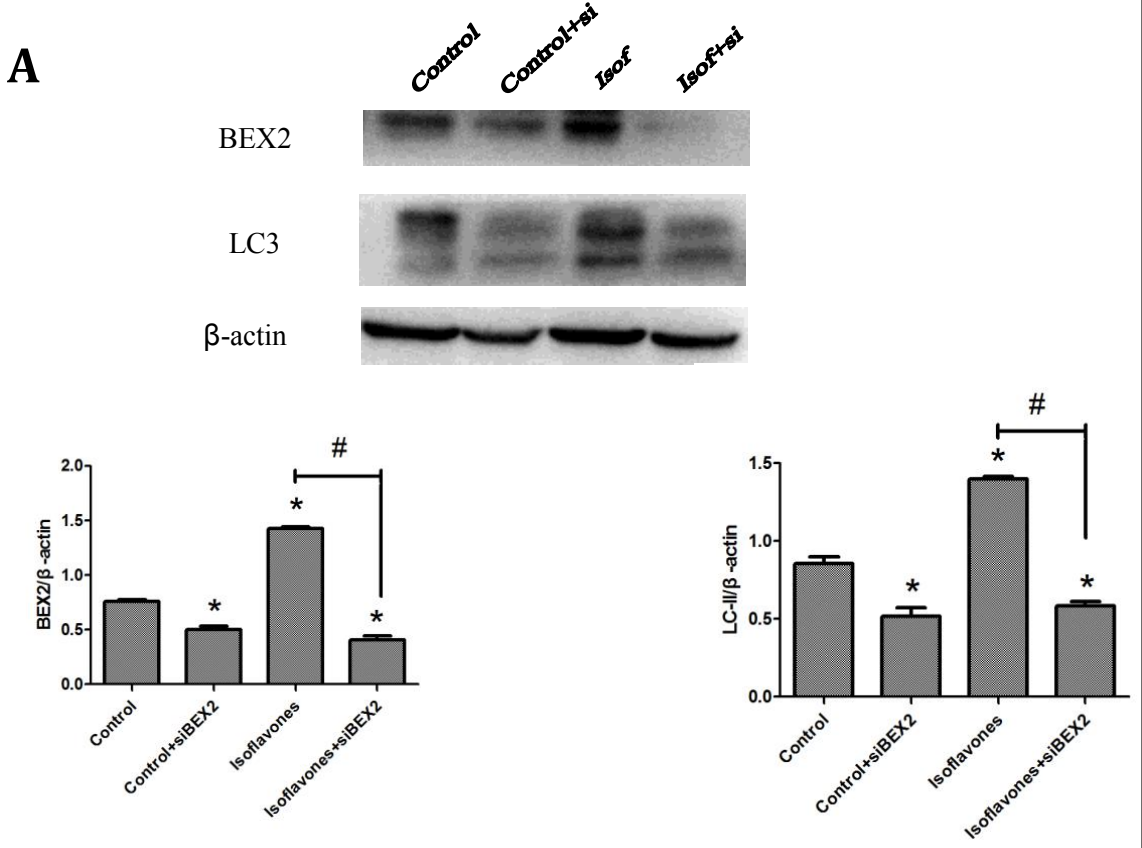

B

BEX2

LC3

$\beta$-actin
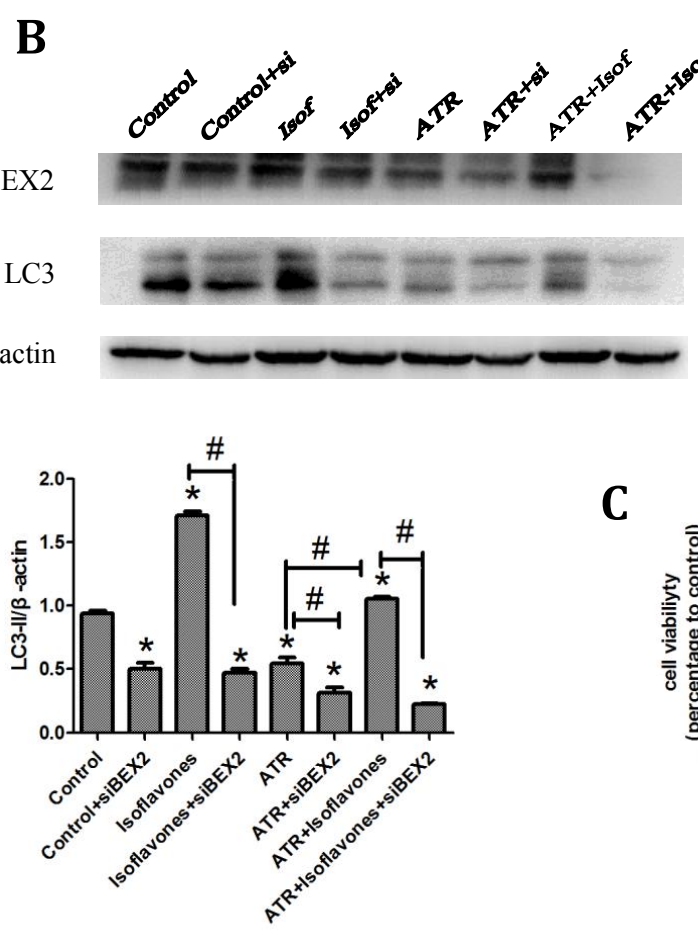

C
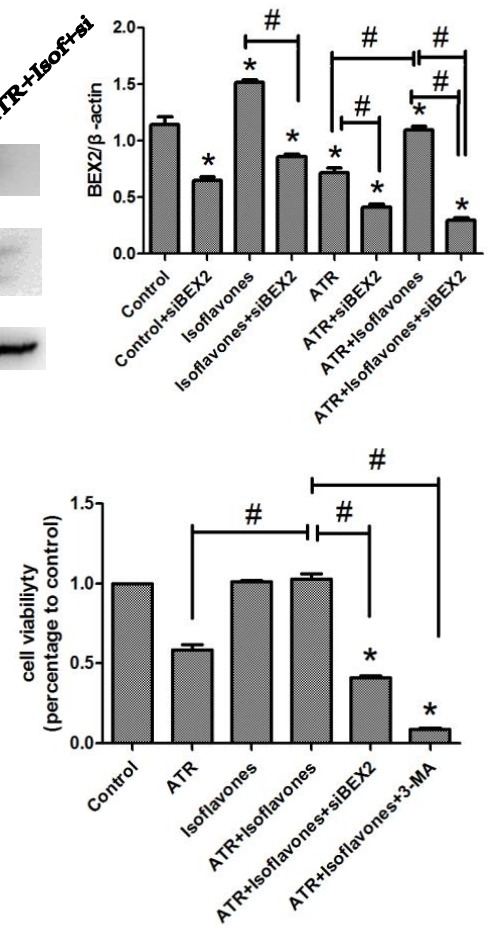


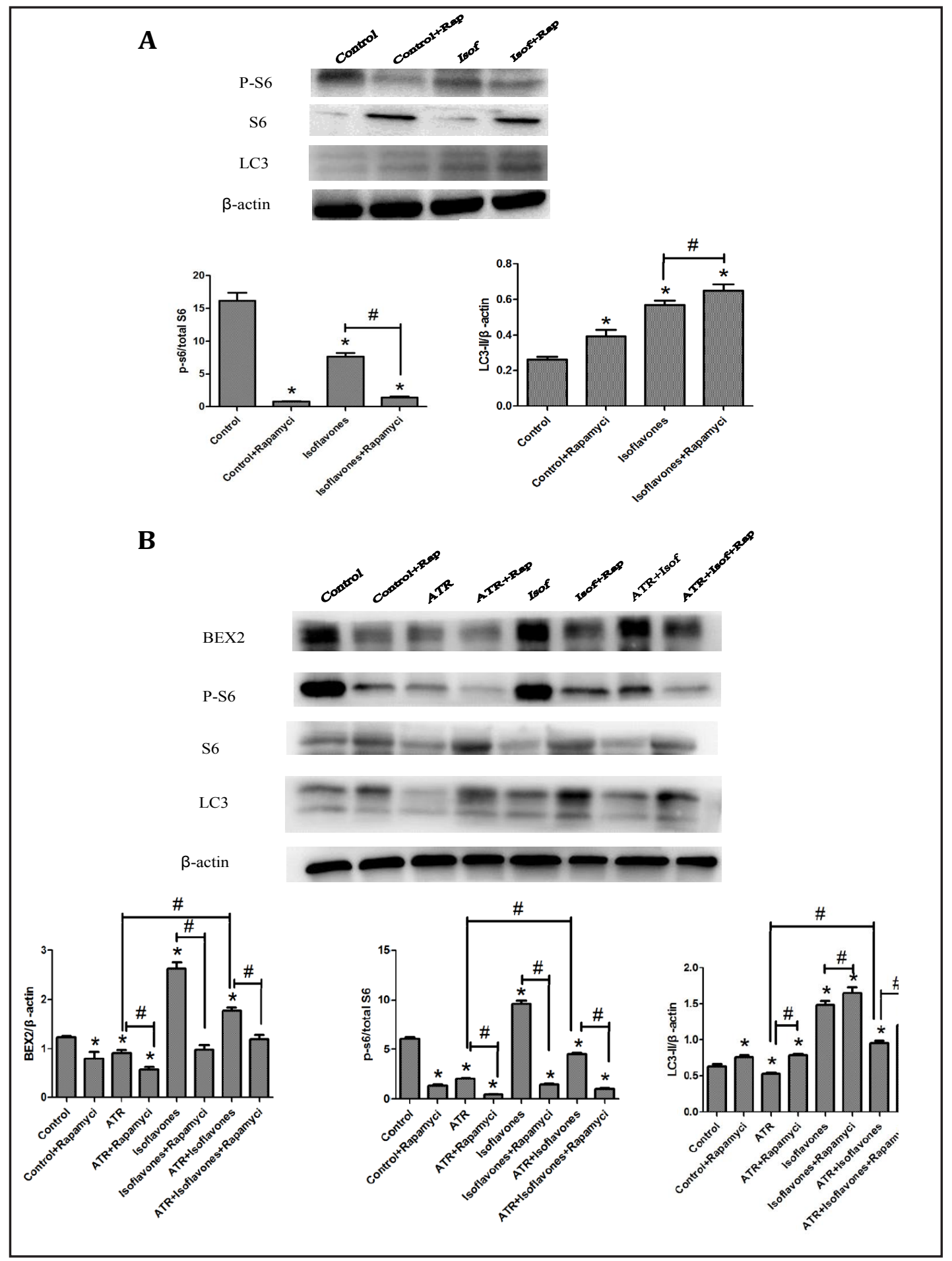

Fig. 6. Isoflavones induce mTOR-dependent autophagy. (A) Cells were pre-treated for $24 \mathrm{~h}$ with $2 \mu \mathrm{M}$ rapamycin (Rap) to inhibit mTOR and then exposed for $24 \mathrm{~h}$ to isoflavones ( $5 \mu \mathrm{M}$, Isof). p-S6, S6, and LC3 expression were determined by western blotting and quantitative analysis using ImageJ. Data were normalized to $\beta$-actin levels. (B) Cells were treated as described in Fig. 6A, then exposed for 24 h to ATR (250 $\mu \mathrm{M})$. BEX2, p-S6, S6, and LC3 expression were determined by western blotting and quantitative analysis using ImageJ. Data were normalized to $\beta$-actin levels. Data represent the mean \pm SD of three independent experiments. Statistical significance was determined by LSD post-hoc test. ${ }^{\#} \mathrm{p}<0.05$ compared between groups. * p<0.05 compared to control.

\section{KARGER}


the protein expression of TH and partially prevented the effect of ATR on TH expression. It is likely that the increase in TH expression may, in part, be due to gene interaction, increased activity and the number of TH+ cells. Together, these data suggest that isoflavones have a crucial effect on ATR-induced neurotoxicity.

Autophagy is active at a basal level in most cells in the body and is a lysosome-mediated degradation process that regulates the turnover of long-lived proteins and eliminates dysfunctional organelles [31]. Autophagy is thought to be a protective mechanism for cells against environmental toxicity [41]. In the present study, we used in vitro experiments to verify that the neuroprotective effects of isoflavones are mediated though increased autophagy. The results show that isoflavones $(5-100 \mu \mathrm{M})$ increase LC3-II expression and degrade p62. LC3-II expression changed significantly after $12 \mathrm{~h}$ of isoflavone $(5 \mu \mathrm{M})$ treatment and peaked at $24 \mathrm{~h}$. Furthermore, compared to ATR alone, cotreatment with ATR and isoflavones significantly increased the level of LC3-II, suggesting that isoflavones mediate neuroprotection through autophagy. It is known that mTORC1 is critical for sensing cellular energy status, and regulates protein levels, cell survival, and autophagy [42]. In this study, our results show that isoflavones $(5 \mu \mathrm{M})$ alone $(24 \mathrm{~h})$ decrease the p-S6 protein and increase the LC3-II protein, which suggests autophagy is activated by isoflavones through the inhibition of mTORC1. In addition, ATR treatment led to a reduction in p-S6 expression, in line with previous reports that ATR induces apoptosis by inhibiting the expression of mTORC1 and p-S6 [43]. ATR treatment also reduced the expression of LC3-II, supported by a recent study that demonstrated ATR mediated autophagy dysregulation in the brain of the common carp [44]. In contrast, ATR has also been reported to induce autophagy [37]. The difference in these findings may result from the dose of ATR, duration of treatment, and experimental models used. In addition, in vitro experiments feature numerous unknown factors that could influence the effects of ATR. Therefore, the issue of whether ATR induces autophagy in SH-SY5Y cells requires further study. Moreover, the ATR-induced reduction of p-S6 and LC3-II expression was partly reversed by isoflavone treatment (Fig. 6). These results indicate that isoflavones have a protective effect on neuronal cells by regulating mTOR-dependent autophagy in the presence of ATR.

BEX2 is abundantly expressed in the central nervous system [33]. BEX2 is a tumor suppressor in human glioma, as overexpression of BEX2 in glioma cells results in suppression of tumor growth in vitro and in vivo [34]. Furthermore, BEX2 can suppress mitochondrial apoptosis [45]. Thus, we hypothesize that isoflavones protect against ATR-induced neuronal death through BEX2-induced autophagy. The present data support this hypothesis because our results show that ATR inhibits BEX2 expression, while combined treatment of isoflavones with ATR restored BEX2 levels. In addition, si-BEX2 significantly abolished the protective effect of isoflavones on ATR-induced cell viability (Fig, 5C). Isoflavonemediated LC3-II expression was also abolished by si-BEX2, supporting the notion that BEX2 activates autophagy and suggesting a pro-survival induction of autophagy via BEX2. These reports demonstrate the critical role of BEX2 in regulating autophagy, which is of particular importance in the present study where BEX2 was associated with isoflavone-mediated autophagic flux in dopaminergic cells. Moreover, BEX2 levels were reduced in the presence of rapamycin to inhibit mTOR, supporting previous reports that mTOR positively regulates BEX2 expression [46]. Further investigation is needed to identify other signaling pathways involved in isoflavone-mediated autophagy induction and BEX2 expression.

With the development of functional genomics in the past several years, long non-coding RNAs (lncRNAs) were found to play crucial roles in the regulation of multiple biological processes, including apoptosis, proliferation, differentiation and metastasis [47-51]. And IncRNAs are known to mediate gene expression regulation through a variety of mechanisms [52]. Furthermore, lncRNAs have been reported as biomarkers for diagnosis of multiple neoplastic diseases, predicting survival [53]. Therefore, identification of BEX2-associated IncRNAs and their roles may provide a useful strategy for diagnosis and prognosis of patients with ATR-induced neurotoxicity; this requires further exploration.

\section{KARGER}


In conclusion, this study shows that ATR suppresses TH and BEX2 expression and increases dopaminergic neuronal death. Isoflavones promote BEX2 expression and induce BEX2-dependent autophagy, which prevent neuronal cell apoptosis induced by ATR. These findings suggest that isoflavones and corresponding mechanisms of neuronal protection are therapeutic candidates for the prevention and/or treatment of neurodegenerative diseases such as PD.

\section{Acknowledgements}

We are grateful to Xue-Ting Li at the Harbin Medical School for critically revising the manuscript. This work was supported by a grant from the National Nature Science Foundation of China (grant number:81273109).

\section{Disclosure Statement}

The authors declare no conflict of interest.

\section{References}

1 Still Poisoning the Well: Atrazine Continues to Contaminate Surface Water and Drinking Water in the United States. 2017/8/12. http://adams.vtls.com:9020/vital/access/manager/Repository/kcpl:9699

2 Decision Documents for Atrazine. 2017/8/12. http://www.epa.gov/opp00001/chem_search/reg_actions/ reregistration/red_PC-080803_080801-Apr-080806.pdf

3 Basic Information about Atrazine in Drinking Water. 2017/8/12. http://water.epa.gov/drink/ contaminants/basicinformation/atrazine.cfm

4 USDA National Agricultural Statistics Service. 2017/8/12. http://quickstats.nass.usda. gov/?sectordesc=ENVIRONMENTAL

-5 Adgate JL, Barr DB, Clayton CA, Eberly LE, Freeman N, Lioy PJ, Needham LL, Pellizzari ED, Quackenboss JJ, Roy, A: Measurement of children's exposure to pesticides: analysis of urinary metabolite levels in a probability-based sample. Environ Health Perspect 2001;109:583-590.

6 Bakke B, De Roos AJ, Barr DB, Stewart PA, Blair A, Freeman LB, Lynch CF, Allen RH, Alavanja MC, Vermeulen R: Exposure to atrazine and selected non-persistent pesticides among corn farmers during a growing season. J Expo Sci Environ Epidemiol 2009;19:544-554.

7 Curwin BD, Hein MJ, Sanderson WT, Striley C, Heederik D, Kromhout H, Reynolds SJ, Alavanja MC: Urinary pesticide concentrations among children, mothers and fathers living in farm and non-farm households in iowa. Ann Occup Hyg 2007;51:53-65.

8 Jablonowski ND, Schaffer A, Burauel P: Still present after all these years: persistence plus potential toxicity raise questions about the use of atrazine. Environ Sci Pollut Res Int 2011;18:328-331.

$\rightarrow 9$ Konstantinou IK, Hela DG, Albanis TA. The status of pesticide pollution in surface waters (rivers and lakes) of Greece. Part I. Review on occurrence and levels. Environ Pollut 2006;141:555-570.

10 Campos-Pereira FD, Oliveira CA, Pigoso AA, Silva-Zacarin EC, Barbieri R, Spatti EF, Marin-Morales MA, Severi-Aguiar GD: Early cytotoxic and genotoxic effects of atrazine on Wistar rat liver: a morphological, immunohistochemical, biochemical, and molecular study. Ecotoxicol Environ Saf 2012;78:170-177.

11 Foradori CD, Hinds LR, Quihuis AM, Lacagnina AF, Breckenridge CB, Handa RJ: The differential effect of atrazine on luteinizing hormone release in adrenalectomized adult female Wistar rats. Biol Reprod 2011;85:684-689.

12 Foradori CD, Zimmerman AD, Hinds LR, Zuloaga KL, Breckenridge CB, Handa RJ: Atrazine inhibits pulsatile gonadotropin-releasing hormone (GnRH) release without altering GnRH messenger RNA or protein levels in the female rat. Biol Reprod 2013;88:9.

13 Liu Z, Fu Z, Jin Y: Immunotoxic effects of atrazine and its main metabolites at environmental relevant concentrations on larval zebrafish (Danio rerio). Chemosphere 2017;166:212-220. 


\section{Cellular Physiology Cell Physiol Biochem 2017;43:1866-1879 \begin{tabular}{l|l|l} 
and Biochemistry & Published onlIne: October 19, 2017 & $\begin{array}{l}\text { (c) } 2017 \text { The Author(s). Published by S. Karger AG, Basel } \\
\text { www.karger.com/cpb }\end{array}$
\end{tabular}}

Li et al.: Isoflavones Against ATR in SH-SY5Y Cells

14 Rayner JL, Fenton SE: Atrazine: an environmental endocrine disruptor that alters mammary gland development and tumor susceptibility; in Environment and breast cancer. Springer, 2011, pp 167-183.

15 Lin Z, Dodd CA, Xiao S, Krishna S, Ye X, Filipov NM: Gestational and lactational exposure to atrazine via the drinking water causes specific behavioral deficits and selectively alters monoaminergic systems in C57BL/6 mouse dams, juvenile and adult offspring. Toxicol Sci 2014;141:90-102.

16 Pogrmic-Majkic K, Fa S, Samardzija D, Hrubik J, Kaisarevic S, Andric N: Atrazine activates multiple signaling pathways enhancing the rapid hCG-induced androgenesis in rat Leydig cells. Toxicology 2016;368-369:3745 .

17 Wang H, Mu S, Zhang F, Wang H, Liu H, Zhang H, Kang X. Effects of Atrazine on the Development of Neural System of Zebrafish, Danio rerio. BioMed Res Int 2015;2015:976068.

18 Bardullas U, Giordano M, Rodriguez VM: Chronic atrazine exposure causes disruption of the spontaneous locomotor activity and alters the striatal dopaminergic system of the male Sprague-Dawley rat. Neurotoxicol Teratol 2011;33:263-272.

19 Bardullas U, Giordano M, Rodriguez VM: Atrazine is primarily responsible for the toxicity of long-term exposure to a combination of atrazine and inorganic arsenic in the nigrostriatal system of the albino rat. Neurotoxicol Teratol 2013;40:59-66.

20 Brown TP, Rumsby PC, Capleton AC, Rushton L, Levy LS: Pesticides and Parkinson's disease - Is there a link? Environ Health Perspect 2005;114:156-164.

21 Hines CJ, Deddens JA, Lu C, Fenske R, Striley CA: Mixed-effect models for evaluating multiple measures of atrazine exposure among custom applicators. J Occup Environ Hyg 2006;3:274-283.

22 Priyadarshi A, Khuder SA, Schaub EA, Shrivastava S: A meta-analysis of Parkinson's disease and exposure to pesticides. Neurotoxicology 2000;21:435-440.

-23 Rodriguez VM, Limon-Pacheco JH, Mendoza-Trejo MS, Gonzalez-Gallardo A, Hernandez-Plata I, Giordano M: Repeated exposure to the herbicide atrazine alters locomotor activity and the nigrostriatal dopaminergic system of the albino rat. Neurotoxicology 2013;34:82-94.

24 Cooper JR, Bloom FE, Roth RH: The Biochemical Basis of Neuropharmacology. USA, Oxford University Press, 2003.

25 Lin Z, Dodd CA, Filipov NM: Short-term atrazine exposure causes behavioral deficits and disrupts monoaminergic systems in male C57BL/6 mice. Neurotoxicol Teratol 2013;39:26-35.

26 Beal MF: Experimental models of Parkinson's disease. Nat Rev Neurosci 2001;2:325-324.

27 Ma K, Wu H-Y, Zhang B, He X, Li B-X: Neurotoxicity effects of atrazine-induced SH-SY5Y human dopaminergic neuroblastoma cells via microglial activation. Mol BioSyst 2015;11:2915-2924.

28 Abarikwu SO, Farombi EO, Kashyap MP, Pant AB: Kolaviron protects apoptotic cell death in PC12 cells exposed to atrazine. Free Radic Res 2011;45:1061-1073.

29 Björklund A, Dunnett SB: Dopamine neuron systems in the brain: an update. Trends Neurosci 2007;30:194-202.

-30 Filipov NM, Stewart MA, Carr RL, Sistrunk SC: Dopaminergic toxicity of the herbicide atrazine in rat striatal slices. Toxicology 2007;232:68-78.

31 Levine B, Klionsky DJ: Development by self-digestion: molecular mechanisms and biological functions of autophagy. Dev Cell 2004;6:463-477.

-32 Thayyullathil F, Rahman A, Pallichankandy S, Patel M, Galadari S: ROS-dependent prostate apoptosis response-4 (Par-4) up-regulation and ceramide generation are the prime signaling events associated with curcumin-induced autophagic cell death in human malignant glioma. FEBS Open Bio 2014;4:763-776.

-33 Alvarez E, Zhou W, Witta SE, Freed CR: Characterization of the Bex gene family in humans, mice, and rats. Gene 2005;357:18-28.

34 Foltz G, Ryu G-Y, Yoon J-G, Nelson T, Fahey J, Frakes A, Lee H, Field L, Zander K, Sibenaller Z: Genomewide analysis of epigenetic silencing identifies BEX1 and BEX2 as candidate tumor suppressor genes in malignant glioma. Cancer Res 2006;66:6665-6674.

35 Lin C-Y, Tsai C-W: Carnosic acid attenuates 6-hydroxydopamine-induced neurotoxicity in SH-SY5Y cells by inducing autophagy through an enhanced interaction of parkin and Beclin1. Mol Neurobiol 2017;54:28132822.

-36 Lin T-K, Chen S-D, Chuang Y-C, Lin H-Y, Huang C-R, Chuang J-H, Wang P-W, Huang S-T, Tiao M-M, Chen J-B: Resveratrol partially prevents rotenone-induced neurotoxicity in dopaminergic SH-SY5Y cells through induction of heme oxygenase-1 dependent autophagy. Int J Mol Sci 2014;15:1625-1646. 


\section{Cellular Physiology Cell Physiol Biochem 2017;43:1866-1879 \begin{tabular}{l|l} 
DOI: 10.1159/000484075 & $\begin{array}{l}\text { O 2017 The Author(s). Published by S. Karger AG, Basel } \\
\text { www.karger.com/cpb }\end{array}$
\end{tabular}}

-37 Song X-Y, Li J-N, Wu Y-P, Zhang B, Li B-X: Atrazine causes autophagy-and apoptosis-related neurodegenerative effects in dopaminergic neurons in the rat nigrostriatal dopaminergic system. Int J Mol Sci 2015;16:13490-13506. Choi AM, Ryter SW, Levine B: Autophagy in human health and disease. N Engl J Med 2013;368:651-662. Bjørkøy G, Lamark T, Brech A, Outzen H, Perander M, Øvervatn A, Stenmark H, Johansen T: p62/SQSTM1 forms protein aggregates degraded by autophagy and has a protective effect on huntingtin-induced cell death. J Cell Biol 2005;171:603-614.

-40 De Lella Ezcurra AL, Chertoff M, Ferrari C, Graciarena M, Pitossi F: Chronic expression of low levels of tumor necrosis factor- $\alpha$ in the substantia nigra elicits progressive neurodegeneration, delayed motor symptoms and microglia/macrophage activation. Neurobiol Dis 2010;37:630-640.

41 Kim JY, Cho TJ, Woo BH, Choi KU, Lee CH, Ryu MH, Park HR: Curcumin-induced autophagy contributes to the decreased survival of oral cancer cells. Arch Oral Biol 2012;57:1018-1025.

-42 Zoncu R, Sabatini DM, Efeyan A: mTOR: from growth signal integration to cancer, diabetes and ageing. Nat Rev Mol Cell Biol 2011;12:21-35.

43 Liu Q, Xu C, Kirubakaran S, Zhang X, Hur W, Liu Y, Kwiatkowski NP, Wang J, Westover KD, Gao P: Characterization of Torin2, an ATP-competitive inhibitor of mTOR, ATM, and ATR. Cancer Res 2013;73:2574-2586.

44 Chen D, Zhang Z, Yao H, Liang Y, Xing H, Xu S: Effects of atrazine and chlorpyrifos on oxidative stressinduced autophagy in the immune organs of common carp (Cyprinus carpio L.). Fish Shellfish Immunol 2015;44:12-20.

45 Naderi A, Liu J, Bennett IC: BEX2 regulates mitochondrial apoptosis and G1 cell cycle in breast cancer. Int J Cancer 2010;126:1596-1610.

-46 Hu Z, Wang Y, Huang F, Chen R, Li C, Wang F, Goto J, Kwiatkowski DJ, Wdzieczak-Bakala J, Tu P: Brainexpressed X-linked 2 is pivotal for hyperactive mechanistic target of Rapamycin (mTOR)-mediated tumorigenesis. J Biol Chem 2015;290:25756-25765.

-47 Dong L, Ni J, Hu W, Yu C, Li H: Upregulation of long non-coding RNA plncRNA-1 promotes metastasis and induces epithelial-mesenchymal transition in hepatocellular carcinoma. Cell Physiol Biochem 2016;38:836-846.

48 Li C, Chen J, Zhang K, Feng B, Wang R, Chen L: Progress and prospects of long noncoding RNAs (lncRNAs) in hepatocellular carcinoma. Cell Physiol Biochem 2015;36:423-434.

49 Li J, Wang X, Tang J, Jiang R, Zhang W, Ji J, Sun B. HULC and Linc00152 act as novel biomarkers in predicting diagnosis of hepatocellular carcinoma. Cell Physiol Biochem 2015;37:687-696.

50 Pan Y, Li C, Chen J, Zhang K, Chu X, Wang R, Chen L: The emerging roles of long noncoding RNA ROR (lincRNA-ROR) and its possible mechanisms in human cancers. Cell Physiol Biochem 2016;40:219-229.

51 Wang F, Yang H, Deng Z, Su Y, Fang Q, Yin Z: HOX antisense lincRNA HOXA-AS2 promotes tumorigenesis of hepatocellular carcinoma. Cell Physiol Biochem 2016;40:287-296.

52 Taft RJ, Pang K C, Mercer TR, Dinger M, Mattick JS: Non-coding RNAs: regulators of disease. J Pathol 2010;220:126-139.

-53 Huang R, Wang X, Zhang W, Zhangyuan G, Jin K, Yu W, Xie Y, Xu X, Wang H, Sun B: Down-regulation of LncRNA DGCR5 correlates with poor prognosis in hepatocellular carcinoma. Cell Physiol Biochem 2016;40:707-715. 